\title{
Imagem urbana: um olhar antropológico sobre o ambiente londrinense
}

\section{Urban image: an anthropological view about the environment of the city of Londrina}

\begin{abstract}
Sergio Marilson Kulak
Universidade Estadual de Londrina - UEL

Mestrando em Comunicação pela Universidade Estadual de Londrina (UEL). Graduado em Comunicação Social - Habilitação Publicidade e Propaganda, pela Universidade Estadual do Centro-

Oeste (Unicentro). Bolsista CAPES.
\end{abstract}

Ana Paula Silva Oliveira

Universidade Estadual de Londrina - UEL

Pós-doutoranda, bolsista CAPES e investigadora do grupo de pesquisa Telejornalismo e linguagens do mestrado em Comunicação da Universidade Estadual de Londrina (UEL). Doutora em Filosofia pela Universidade do Porto, Portugal. Mestre em Comunicação e Semiótica pela PUC-São Paulo. Jornalista formada pela Faculdade Cásper Líbero, SP.

\section{Resumo}

A presente pesquisa analisa o modo como determinados ambientes da cidade emanam sentidos a partir dos signos que compóem sua imagem urbana, sobretudo, os visuais, originando nos expectadores da imagem da cidade determinadas acepçôes que culminam em representaçôes. Estas, por sua vez, são resultados da interação entre sujeito e espaço, e só são possíveis devido à intervenção racional que o expectador faz do ambiente. $\mathrm{O}$ corpus escolhido para análise são três bairros que compóem o ambiente urbano da cidade de Londrina, Paraná, sendo estes: Gleba Palhano, Jardim Cláudia e Guanabara. Como base teórica, o estudo se vale dos conceitos de antropologia urbana e dos estudos sobre as manifestaçóes da imagem da cidade a partir de Lucrécia D’Alessio Ferrara, Kevin Lynch e Massimo Canevacci.

Palavras-chave: Espaço Urbano; Cidade; Representação.

\begin{abstract}
This research examines how certain environments of the city emanate senses from the signs that comprise the urban image, especially, the visual signs, causing in the spectators of the image of the city particular senses, that culminate in certain representations. These, thus, are the result of the interaction between subject and space, and it is only possible because of rational intervention that the viewer makes on the environment. To make the analysis, we chose as corpus three districts that compose the urban environment of the city of Londrina, Paraná: Gleba Palhano, Jardim Claudia and Guanabara. As a theoretical basis, the study makes use of the concepts of urban anthropology and the study of the manifestations of the image of the city by Lucrécia D'Alessio Ferrara, Kevin Lynch and Massimo Canevacci.
\end{abstract}

Keywords: Urban Space; City; Representation. 


\section{Introdução}

A vida em sociedade é repleta de manifestaçóes e acontecimentos. Seja em casa, na escola ou no trabalho, entre outros, estamos constantemente nos movendo em verdadeiras interaçóes com o ambiente. Portanto, para que possamos dar sentido ao nosso cotidiano, é necessário, antes, estarmos em algum espaço físico, pois, toda a nossa vivência acontece em algum "lugar", isto é, um ambiente repleto de significações.

Significamos os ambientes de acordo com o uso com que fazemos deles. Por exemplo, a casa passa a ser o ambiente da família, do descanso, o ambiente que é sua propriedade. Já o trabalho é o lugar onde existem determinadas obrigaçóes, se exerce uma atividade e se trabalha em equipe com uma finalidade específica. A igreja, por sua vez, é o espaço da reflexão, da fé. O que difere estes três ambientes já que ambos são edificações feitas de materiais fisicamente semelhantes? São os usos e hábitos que fazemos deles. As pessoas, de modo geral, classificam determinadas qualidades a cada um destes ambientes, fazendo com que eles assumam diferentes representaçóes em cada vivência.

Nos ambientes da cidade acontece da mesma forma. As manifestaçôes plurais que ocorrem no dia a dia concebem diferentes aspectos com os quais seus habitantes irão se deparar e, consequentemente, formular a sua imagem urbana. Nesse aspecto, enquadra-se o objeto de estudo do presente artigo: os bairros Gleba Palhano, Jardim Claudia e Guanabara que, mesmo tão próximos geograficamente, assumem tipos de representação totalmente diferentes no ambiente urbano de Londrina, quarta maior cidade do Sul do Brasil e segunda maior do Paraná. A Gleba Palhano, em meio à verticalidade de seus prédios, emana sentidos de riqueza, glamour, sofisticação, enquanto os bairros vizinhos - Jardim Claudia e Guanabara - apresentam residências de aspectos mais simples, algumas ainda em madeira e com os sinais desgastados do decorrer do tempo, com ruas ainda por asfaltar. Dessa forma, lança-se a questão norteadora do estudo: como tamanhas diferenças convivem em espaços geograficamente tão próximos?

Para apoiar esta reflexáo, seráo utilizados conceitos antropológicos do espaço urbano segundo Lucrécia D’Alessio Ferrara (1986, 1993, 2002), Massimo Canevacci (1997) e Kevin Lynch (1999). A área de recorte centra-se no espaço urbano de Londrina, mais especificamente em três bairros localizados na região sul da cidade: Gleba Palhano, Jardim Claudia e Guanabara. Para a análise foram utilizadas fotografias elaboradas pelo autor especificamente para o estudo, que ilustram os traços e as diferenças destes ambientes urbanos..

\section{O ambiente como local de representaçáo}

A visualidade se faz um elemento constante em nossa sociedade. Nosso cotidiano é povoado por diferentes signos que emergem pelas ruas formando uma verdadeira imagem urbana. A imagem da cidade apresenta uma pluralidade sinestésica, isto é, sua composição é exercida não só por 
elementos visuais, mas, também, por elementos sonoros, cinéticos, olfativos e táteis, gerando uma ampla capacidade de representaçáo em determinado espaço físico.

Tendo em vista que a cidade se faz uma construção no espaço, cada cidadão construirá, cotidianamente, uma relação com ela por meio de sua vivência e das informaçóes urbanas com as quais tem contato, promovendo associaçóes e, assim, impregnando-as de significados. Dessa maneira, cada pessoa irá criar algum tipo de relação com o ambiente que culminará em uma representação, em uma imagem urbana. Contudo, segundo Ferrara (1993) essa imagem não é rígida, mas é percebida em um processo dinâmico, corrente e seletivo, no qual o indivíduo apreende a representação a partir de seu repertório individual ou do repertório coletivo.

No território urbano, o corpo do sujeito e o corpo da cidade formam um, estando
o corpo do sujeito atado ao corpo da cidade, de tal modo que o destino de um não
se separa do destino de outro. Em suas inúmeras e variadas dimensóes: material,
cultural, econômica, histórica etc. O corpo social e o corpo urbano formam um
só. Para nossa época, a cidade é uma realidade que se impóe com toda sua força.
Nada pode ser pensado sem a cidade como pano de fundo. Todas as determinaçôes
que definem um espaço, um sujeito, uma vida cruzam-se no espaço da cidade.
(ORLANDI, 2004, p.11)

De acordo com Canevacci (1997, p.35), "compreender a cidade significa colher fragmentos. E lançar sobre eles estranhas pontes, por intermédio das quais seja possível encontrar uma pluralidade de significados". Para o autor, náo apenas vivemos na cidade como também somos vividos por ela. De fato, a relação que se desenvolve com o ambiente acontece a partir de suas manifestaçôes, pelos movimentos que engendram a sociedade, o habitante passa a viver a cidade em suas transformaçóes e a consumi-la por intermédio da experiência.

Um dos principais modos desse consumo se dá pela exploração visual. Isso é possível graças ao design do ambiente. Para Lynch (1999, p.51), "a cidade é uma sobreposição de imagens individuais" e cada pessoa inserida nela desenvolverá uma imagem do ambiente a partir de sua percepção, criando uma imaginabilidade do lugar, ou seja, promovendo uma imagem mental de um dado espaço físico a partir das características deste ambiente, sobretudo as visuais, que servirão como âncoras e índices de localização e reconhecimento do local. Essa imagem será carregada com os significados que impomos a estes locais, classificando-os como lugares, isto é, ambientes que nos transmitem uma mensagem, uma representaçáo. "A imagem mental que gravamos da cidade concentra-se um requisito básico: a sua qualidade visual" (FERRARA, 1993, p. 252). Dessa forma, o design presente nas ruas, calçadas, praças, marcos, casas, edifícios, etc., servirá como um gancho na memória do observador.

A cidade é o lugar do olhar. Por esse motivo a comunicação visual se torna o seu traço característico. [...] A comunicação é a viagem da diferença que contém 
o sentido da informação. A comunicação urbana exacerba essas diferenças, multiplica-as, fá-las coexistir, e entrar em conflito. (CANEVACCI, 1997, p. 43)

Como afirma Canevacci (1997), a comunicação visual se faz a principal característica da imagem urbana, ainda que seja polifônica, a visualidade dos elementos da cidade permite que se crie uma imaginabilidade do lugar. A partir da imagem do elemento físico e de suas características, são acessadas mentalmente determinadas informaçóes, tal como um processo de simbolização, que age em semiose, isto é, um signo que remete a outro signo, fazendo com que haja uma significação do ambiente, seja esta plena ou parcial.

Construir uma imagem ambiental é vital para a vivência do ser humano em sociedade e, por isso, ela acaba surgindo como consequência do cotidiano do observador. Para Lynch (1999, p.7), a imagem ambiental é um produto "de um processo bilateral entre observador e seu ambiente, $\mathrm{O}$ observador seleciona, organiza e confere significado àquilo que vê. Assim, a imagem varia de acordo com cada observador". A representação urbana se caracterizará quando o sujeito interpretante "for capaz de produzir sobre os signos que povoam a cidade, um juízo perceptivo que o encaminhe para uma ação crítica e interveniente sobre o urbano" (FERRARA, 1993, p. 260).

De acordo com Lynch (1999), a imagem ambiental é composta a partir de três fatores que ocorrem simultaneamente: a) identidade: é o que a identifica como aquele espaço e não outro, ou seja, sua unicidade. Entende-se aqui o conceito de individualidade, o lugar enquanto único e de entidade separável; b) estrutura, que se refere a sua relação físico-espacial, o objeto está em uma "relação espacial ou paradigmática do objeto com o observador e os outros objetos" (LYNCH, 1999, p. 9), e; c) significado, o que simboliza o ambiente/objeto e este passa a representar algo para alguém, está diretamente ligado aos itens anteriores. Para o autor, os significados singulares da cidade são imensamente variáveis.

Entretanto, devido o alto grau de interatividade entre observador e ambiente, os significados podem ser moldados e reformulados constantemente com base em uma mesma imagem ambiental, isto é, a cidade e seus espaços podem adquirir novas representaçóes com o tempo, pois ela vive em um processo contínuo de mutação e, com isso, as transformaçôes do espaço passam a gerar novas representaçóes. Neste aspecto se inserem os elementos visuais. Para que um espaço possa significar, é preciso, a priori, ter o elemento físico para significá-lo, como uma espécie de invólucro, ou ainda, em uma metáfora, tal qual o corpo serve de morada à alma, o espaço abriga os seus significados, pois são estes que lhe garantem a qualidade de lugar.

Por exemplo, nenhum calçadão é tão facilmente reconhecido em todo o Brasil quanto o da praia de Copacabana, no Rio de Janeiro. Suas curvas e traços em petitpavet são identificados facilmente pelos brasileiros, seja qual for a sua região de origem, pois o lugar apresenta um amplo caráter simbólico. 
Figura 1: Calçadão da praia de Copacabana, Rio de Janeiro

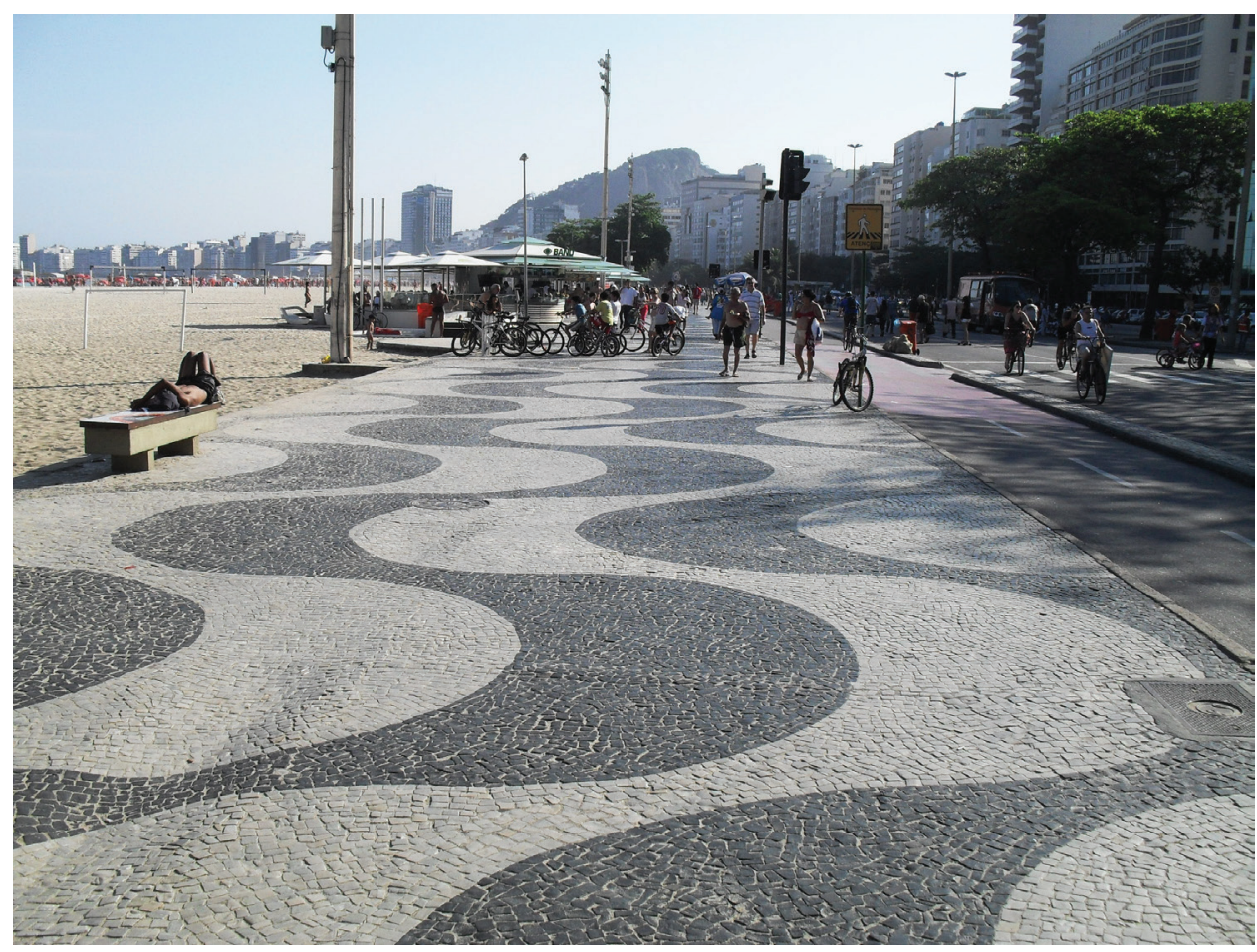

Fonte: Arquivo pessoal do autor.

Isso acontece porque determinadas formas tendem a captar mais facilmente a nossa atenção, fazendo com que elas adquiram um alto grau de simbolização. A representação daquele espaço se mostra mais rica que a de um espaço comum que, geralmente, se assemelha a demais ambientes da cidade e, até mesmo, de demais localidades. O que acontece no exemplo é o fato da calçada ter se tornado um símbolo da cidade devido à sua forma.

O que se sobressai neste ambiente é o design do elemento. A partir de uma forma inusitada, a modelagem da construção garante um amplo poder de simbolização do espaço. Essa simbolizaçáo pode se manifestar em qualquer espaço, seja ele sofisticado e inusitado ou extremamente simplório. Neste sentido, o presente ensaio centrará seus esforços em mostrar como determinados signos presentes nos bairros da Gleba Palhano, do Jardim Claudia e do Guanabara, possuem uma ampla capacidade de representação.

Portanto, para a análise e explanação, o estudo utilizará fotografias elaboradas, pelo autor em momentos de observaçáo de campo. A escolha justifica-se pelo fato de que "uma fotografia pode ser o ponto de partida de uma reflexão antropológica ou o resultado dessa reflexão. [...] Ela descreve, representa ou até mesmo interpreta tudo o que pode ser visto" (GURAN, 2011, p.80).

\section{Análise de material}

A cidade é composta por diferentes elementos autônomos como ruas, prédios, casas, entre outros, que constituem a estruturação denominada contexto 
urbano. O contexto da cidade contribui para a sua significação, sendo assim, qualquer alteração e/ou mudança que ocorra no contexto urbano implicará na modificação daquele significado primeiramente estabelecido. Quando se pensa no ambiente urbano como um todo, vê-se que estes elementos se relacionam entre si, proporcionando a apreensão da cidade como unidade em uma percepção global e contínua. "Entendida como unidade de percepção, a cidade não é mais um dado, mas um processo contextual onde tudo é signo, linguagem" (FERRARA, 1986, p. 119).

O contexto urbano que envolve a região Sul da cidade de Londrina, onde se localizam os bairros estudados, mostra-se heterogêneo. É possível notar como, dentro de um mesmo ambiente, as formas coexistem, misturam-se e se relacionam em amálgamas que compóe a imagem urbana dessa região. A diferenciação presente neste ambiente londrinense é originada a partir dos usos e hábitos aplicados sobre eles.

O bairro Guanabara é composto por residências visualmente mais humildes, na sua maioria são estruturas simples com apenas o piso térreo. Algumas das casas são bastante antigas e confeccionadas com materiais que atualmente são menos utilizados, como a madeira, por exemplo. Além disso, as ruas são estreitas e bastante arborizadas. As casas apresentam uma arquitetura que remete as décadas de 1970 e 1980, algumas delas mostram os traços da passagem do tempo em suas fachadas.

O Jardim Claudia, por sua vez, apresenta uma variedade de pequenas casas junto a sobrados, além de pequenas estruturas de salas comerciais. As casas são mais bem elaboradas visualmente, mas, também, o espaço traz algumas habitaçóes antigas e simplórias. Assim como no Guanabara, o bairro apresenta casas antigas, no entanto, elas estáo próximas a propriedades com arquiteturas mais recentes, sendo notável a coexistência de habitaçôes modernas e antigas. Algumas ruas do bairro ainda são em terra batida, isso se justifica pelo fato de que o bairro se localizava ao extremo da cidade, junto a várias propriedades rurais e, com o passar dos anos, essas propriedades foram adquiridas por grandes corporações imobiliárias, que iniciaram a construção de edifícios, dando origem a Gleba Palhano. Desse modo, os terrenos que ainda estão sem construçôes aglomeram-se perto da divisa dos bairros, fazendo com que não exista um tráfego intenso de automóveis nestas vias, o que adia a pavimentação destas ruas.

Já a Gleba Palhano é o bairro da classe nobre da cidade. Formado por inúmeros prédios, é o local que apresenta o metro quadrado mais caro de Londrina. No bairro predominam os arranha-céus, são diversos os edifícios que ultrapassam os trinta andares. $\mathrm{O}$ número de casas é relativamente inferior à quantidade de prédios, uma vez que, anteriormente, o local era de fazendas e chácaras que foram loteadas e, com o boom imobiliário dos anos 90, passou a incorporar grande parte dos edifícios da cidade. Sendo assim, as grandes corporaçóes imobiliárias já iniciaram a povoação do bairro por meio destas construçôes com 
inúmeros apartamentos.

Figura 2: Mapa via satélite da regiáo selecionada

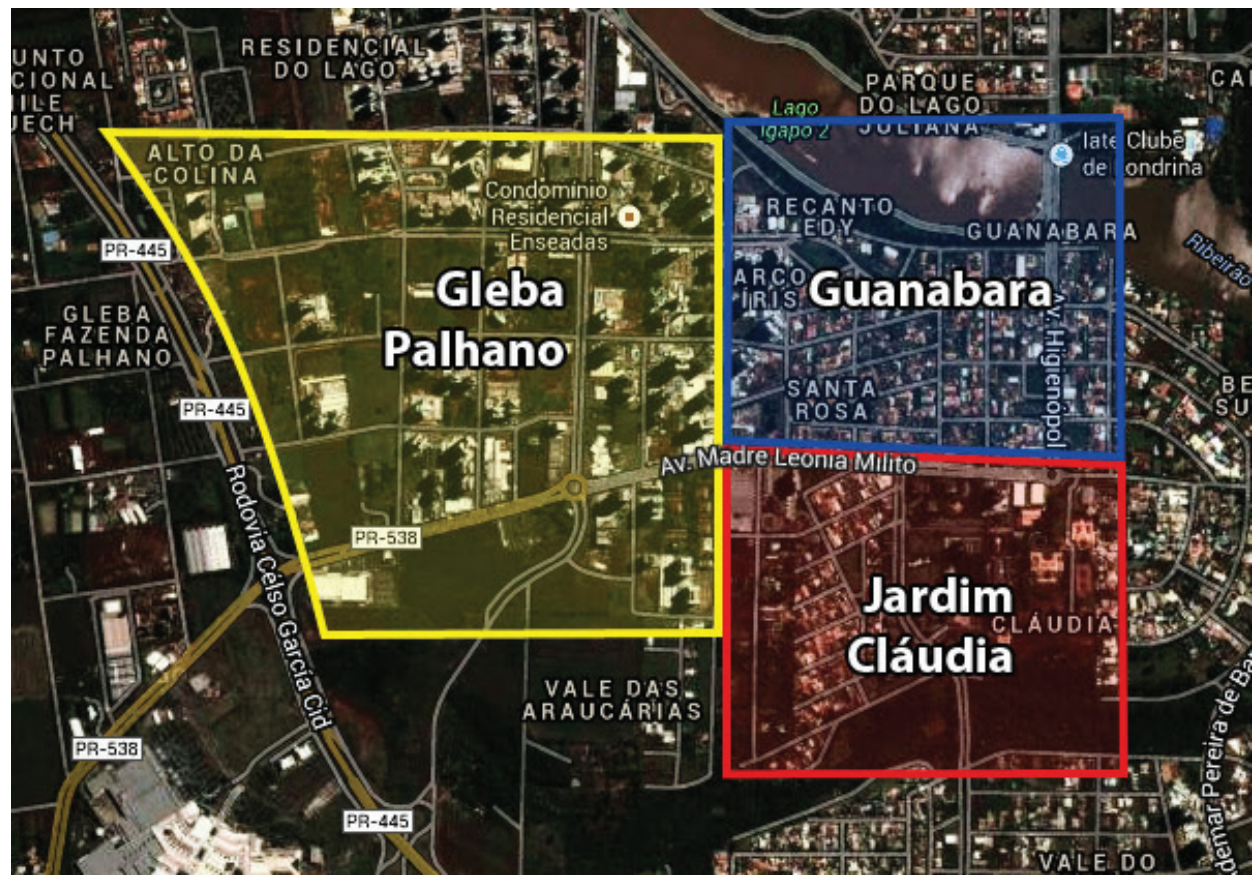

Fonte: Google Maps

A figura 3 ilustra a imagem urbana da região, com os prédios da Gleba posicionados na regiáo central e a direita da fotografia; a regiáo esquerda da imagem ilustra o bairro Guanabara, logo acima do Lago Igapó, sendo uma região de casas térreas; e, mais ao fundo, o Jardim Claudia com poucos prédios, todos de altura bastante inferior se comparados aos do bairro vizinho.

Figura 3: Tomada aérea da região estudada

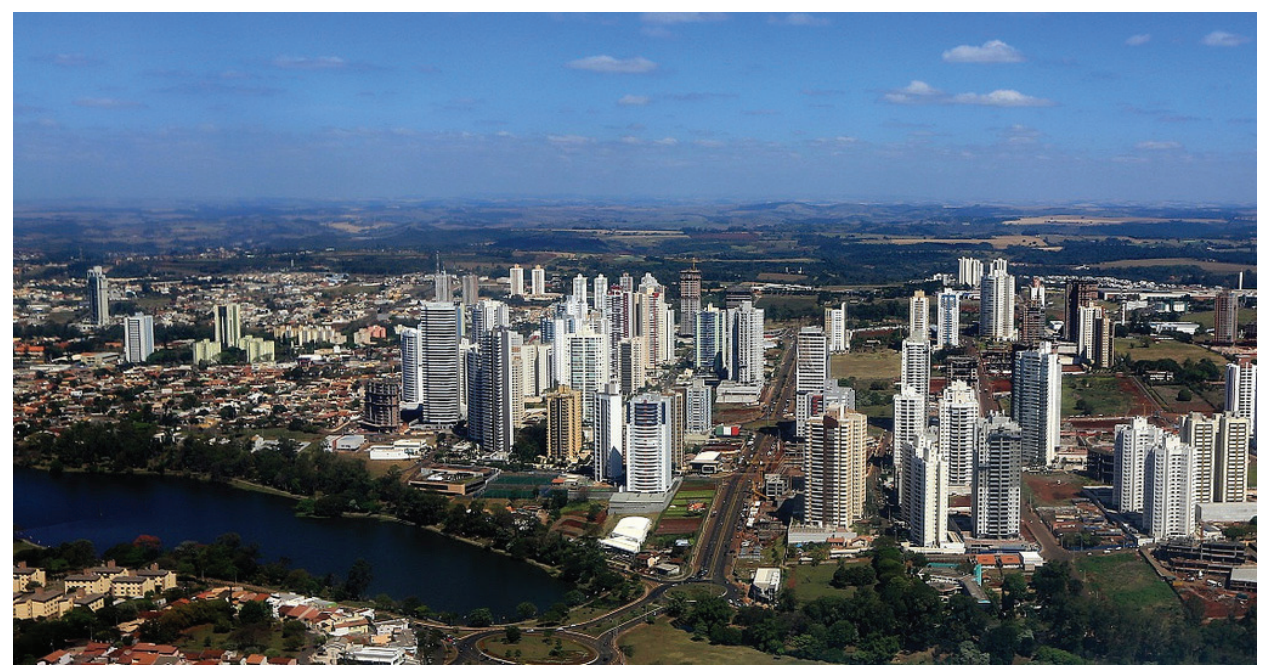

Fonte:http://i1141.photobucket.com/albums/n586/Braulio_Queiroz/CIDADES\%20 BRASILEIRAS/LONDRINA/londrina1-6.jpg.

O bairro da Gleba Palhano destaca-se por seus prédios, todos imponentes em sua verticalidade, a arquitetura do ambiente é bastante moderna e conota o 
alto poder aquisitivo dos moradores da região. As principais vias do local, como as ruas Joáo Wiclif, Ernani Lacerda de Ataíde e a Avenida Airton Senna da Silva, ilustram a disposição dos edifícios que se erguem compondo a imagem urbana da localidade.

Figura 4: Gleba Palhano vista da Avenida Airton Senna da Silva

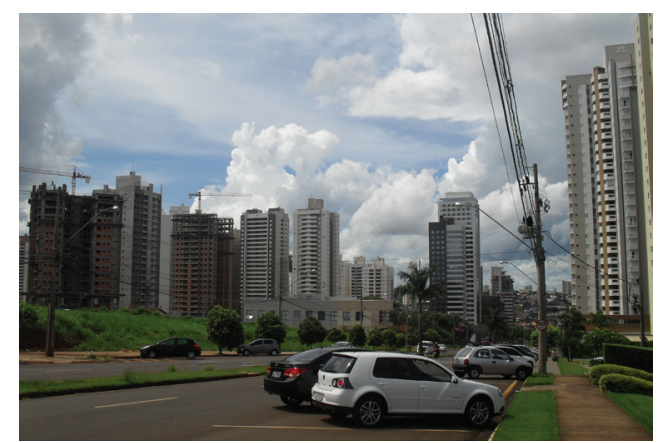

Fonte: Arquivo pessoal do autor

A arquitetura vanguardista da região impressiona. São traços modernos elaborados em concreto e vidros, com fachadas exuberantes repleta de signos indiciais e simbólicos que conotam a qualidade do ambiente, de acordo com Ferrara (1993, p.241), "como signos do espaço social, os índices representam hábitos, usos, valores, expectativas que levaram os usuários a marcar sua intervenção no espaço de determinada maneira”. Segundo ela, os índices são interpretaçóes resultantes do modo como o usuário do ambiente se relaciona com o espaço social, o seu modo de vida. Mais que um bairro povoado pela classe alta, as novas estruturas daquele lugar se moldam para essa camada mais elitizada da população. As altas grades apoiadas sobre os muros repletos de detalhes estéticos são um convite a, literalmente, olhar para cima e contemplar o ambiente. Os verdes impecáveis dos gramados em frente às portarias, juntamente às árvores devidamente podadas, fazem com que o discurso imagético do lugar torne-se ainda mais forte. A imagem urbana da Gleba Palhano destoa totalmente do cinza característico das metrópoles que têm suas ruas povoadas por prédios.

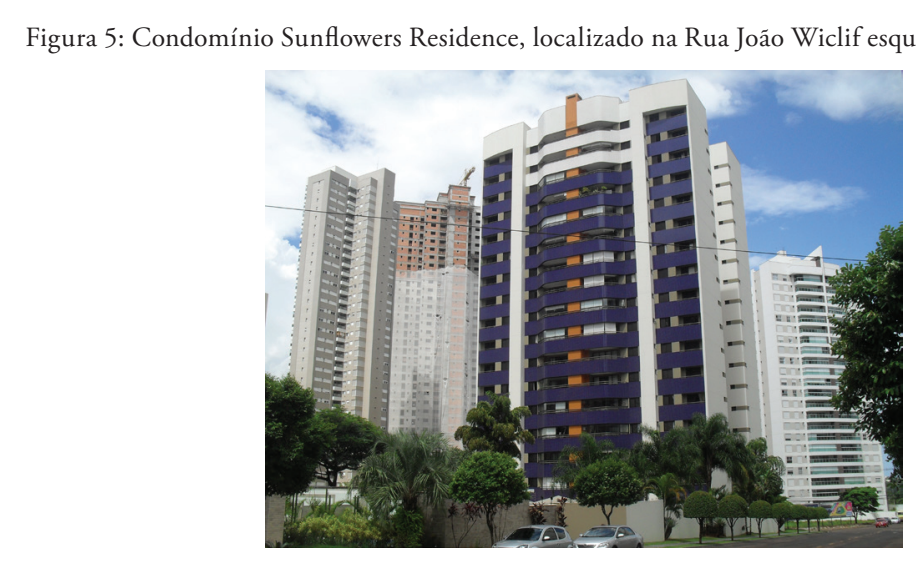

Fonte: Arquivo pessoal do autor

Sabendo que o tipo de representação que a cidade cria nas pessoas é dado 
a partir dos usos e hábitos de cada ambiente, pode-se dizer que a Gleba Palhano gera sentidos que estabelecem uma representação de requinte, luxo e nobreza, atingindo níveis simbólicos a partir dos hábitos estabelecidos pelo próprio ambiente, que são resultantes de uma comunicação de massa difundida pelas corporações imobiliárias que tentam, a todo custo, implantar esta concepção de superioridade do bairro em relação ao restante do município londrinense. Instaurando os três quesitos abordados por Lynch (1997), podemos afirmar que:

- A unicidade do lugar, por meio de sua identidade, isto é, o bairro é único porque apresenta uma infinidade de qualidades que podem ser atribuídas somente a ele no ambiente urbano de Londrina, como já especificado anteriormente;

- Quanto à sua estrutura, o espaço físico que o bairro ocupa, faz dele um lugar privilegiado, pois está próximo à universidade pública e uma das principais faculdades de Londrina, próximo ao bairro existem, ainda, as rodovias de acesso, além disso, o bairro está ao lado de um dos principais cartóes postais da cidade: o Lago Igapó;

- No que tange o seu significado, os sentidos aplicados sobre a Gleba Palhano são sempre no aspecto de melhor lugar da cidade para habitação, com comodidade, luxo e requinte.

Entretanto, toda a riqueza estética que a Gleba Palhano exibe destoa de seus bairros vizinhos, a ver as ruas do bairro Guanabara que se estabelecem imediatamente ao seu lado, na direção leste. O Guanabara, como é conhecido, apresenta uma arquitetura modesta, composto, predominantemente, por casas simples e terrenos estreitos. Muitas habitaçóes mostram que o bairro é antigo, uma vez que seus traços e formas são característicos de outras épocas, como as décadas de 70 e 80 , por exemplo. A imagem do ambiente é composta por vias estreitas e de pouca movimentação, fazendo-se, assim, um lugar tranquilo e pacífico, diferentemente do vizinho rico, ou seja, a Gleba Palhano. Existe a presença de árvores nos espaços externos das casas, entre os muros e as calçadas, todavia, o tratamento dado ao verde do ambiente é bastante diferenciado, é possível perceber certo descuido com a jardinagem, tanto nas ruas e praças, quanto nos terrenos habitados.

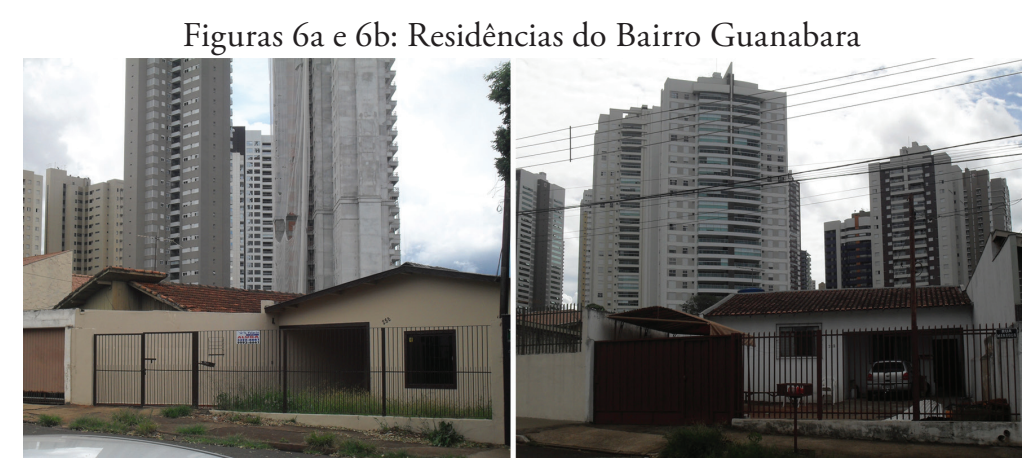

Fonte: Arquivo pessoal do autor

Por meio das fotografias da figura 6 é possível notar a presença de prédios 
ao fundo da imagem. A relação espacial entre os dois bairros é muito próxima, o que gera a incorporação dos edifícios pela imagem urbana do Guanabara. A simplicidade das residências convive diariamente com os prédios monumentais e aqueles ainda em construção. Os moradores do bairro vivenciam em seu cotidiano uma parte da metrópole, adquirindo verdadeiras experiências com construçôes modernas e com a grande movimentação das avenidas da Gleba Palhano, que tanto contrastam com a vida pacata do Guanabara, exceto pela Rua Bento Munhoz da Rocha Neto, que é uma das vias que contorna o Lago Igapó e apresenta um fluxo alto de pedestres, ciclistas e automóveis.

Neste aspecto, enquadra-se a questão da percepção levantada por Ferrara (1993). Para ela, a imagem urbana, enquanto representação, une-se a percepção em um processo de semiose em que, por meio de ligações, são extraídas novas informações a partir dela própria, geradas novas ações, isto é, através da associação via imagem mental criam-se novas imagens urbanas, que são também representaçôes. A percepção vem como a capacidade de apreender as informaçôes tidas cotidianamente na cidade e, a partir de entáo, produzir o conhecimento que estimule outras açôes, comportamentos e manifestaçóes. Para a autora, a percepção urbana é um processo e uma possibilidade, variando de acordo com o repertório sociocultural de cada pessoa.

A percepção tida a partir das representaçóes projetadas no ambiente em questấo varia em um curto espaço, é possível deparar-se com dois ambientes distintos em questão de segundos se o observador estiver em movimento. Por meio da observação, foi possível notar que, de um mesmo ponto fixo em uma via que integra os dois bairros, a percepção que se pode desenvolver é totalmente contrária. A imagem a seguir mostra dois planos fotografados exatamente do mesmo lugar, apenas com uma rotação de $180^{\circ}$ de um em relação ao outro. $\mathrm{O}$ primeiro plano corresponde ao Guanabara e mostra suas casas baixas com suas calçadas assimétricas, já o segundo é a imagem da mesma rua em direção a Gleba Palhano, com seus prédios imponentes, traços característicos e jardinagem com diferentes tipos de árvores, entre outros.

Figuras7a e 7b: Guanabara e Gleba Palhano vistas da Rua Caracas, esquina com a Rua Cayená

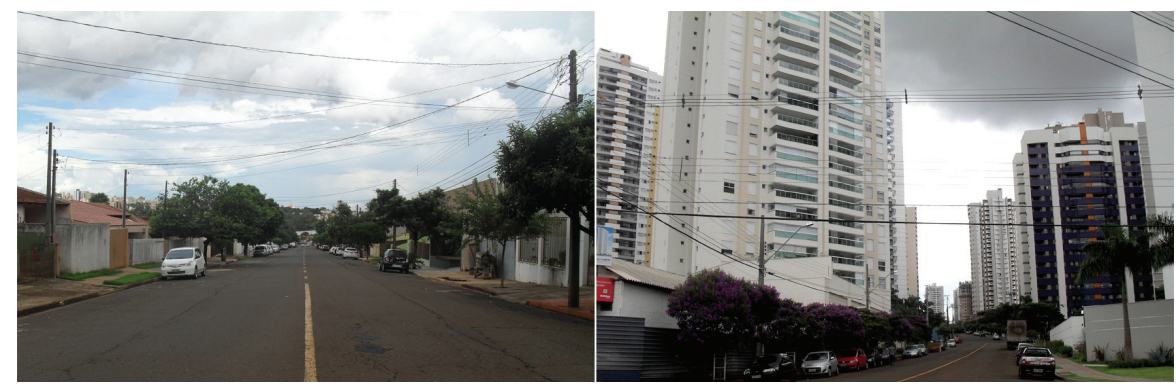

Fonte: Arquivo pessoal do autor

Nessa perspectiva, as representaçóes tidas pelos observadores podem adquirir usos e hábitos diferenciados mesmo em um espaço geográfico próximo. As pessoas podem criar dois tipos de imagens urbanas a partir de um mesmo 
ponto, como neste caso. É de se impressionar a capacidade que ambos os bairros têm em conviver em harmonia mesmo com tanta heterogeneidade. Neste sentido, Canevacci (1997) trata da questão espaço-tempo, as imagens ilustram como o olhar para a Gleba Palhano conota o moderno e novo, com signos de riqueza e poder, ao passo que a visão do Guanabara, ainda que exatamente do mesmo lugar, remete a sentidos de uma história mais antiga, carregando em suas características visuais, toda a carga histórica do bairro e também de Londrina, ambos convivendo a poucos metros de distância, o que resulta em uma percepção simultânea do ambiente urbano.

No contexto metropolitano os indicadores espaço-tempo se fundem numa totalidade nova e concreta: de um lado, o tempo se torna visível, anima-se, tornase carne, ou parede, rua, edifício, de outro lado, o espaço se torna estratificado em história, incorpora o tempo, une os diversos enredos dos contos urbanos. [...] A mistura de grupos étnicos, arranha-céus imponentes, vagabundos desolados, cozinhas, linguagens, costumes, todos provenientes de mundos diversos, mas coexistindo lado a lado, permitem o desenvolvimento de uma percepção sincrônica do espaço e do tempo. (CANEVACCI, 1997, p. 87-88)

Do mesmo modo como acontece no Bairro Guanabara, o Jardim Claudia apresenta essa diferenciação que convive em harmonia com a moderna Gleba Palhano. O bairro se caracteriza pela miscigenação de casas humildes com sobrados bem elaborados, coexistindo arquiteturas antigas e tradicionais com residências modernas, repletas de traços vanguardistas, principalmente ao redor da Avenida Madre Leonia Milito, via que une o Jardim Claudia à Gleba Palhano. É possível perceber que, de certo modo, existe uma necessidade de igualdade por parte do Jardim Claudia, principalmente na Avenida Madre Leonia. Algumas construçôes são muito bem projetadas e com designs modernos, sendo que essa característica é perceptível, principalmente, nos meios comerciais como padarias, salóes de beleza, complexos de salas comerciais, danceterias, dentre outros.

Contudo, ao sair da avenida principal, é possível encontrar grandes contrastes. Com a exceção do complexo de condomínios Quinta da Boa Vista e mais três edifícios presentes no local, o bairro é composto, quase em sua totalidade, por residências térreas, algumas bastante simplórias, ainda em madeira, mas que, assim como no Guanabara, convivem com o desenvolvimento e a efervescência da Gleba Palhano, que se localiza a apenas 200 metros de distância.

Figuras 8a e 8b: Residências do Jardim Claudia na Rua Osaka, ao fundo os prédios da Gleba Palhano
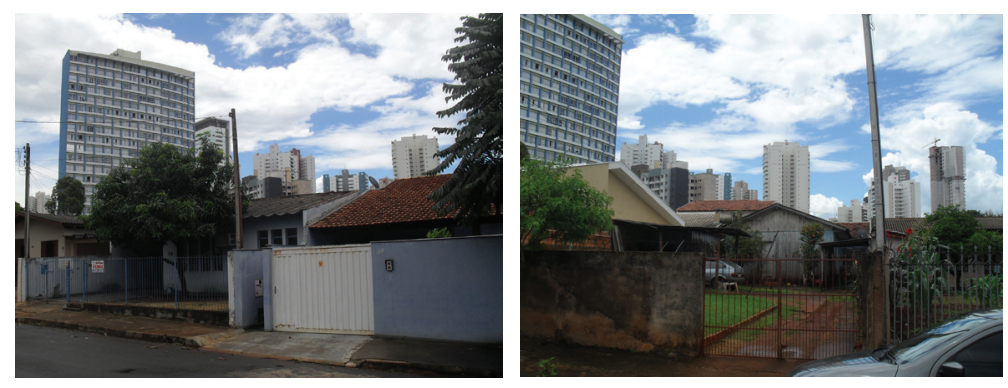

Fonte: Arquivo pessoal do autor 
Ao se locomover dentro do Jardim Claudia, próximo às vias que separam os bairros, é possível encontrar, ainda, grandes problemas urbanos, como a falta de pavimentação de vias e bueiros de saneamento básico em estado precário, tudo isso apenas a uma quadra da Avenida Madre Leonia Milito. Problemas como vegetação alta e lixo em terrenos baldios são comuns nesta parte do bairro, onde, pode-se dizer, apresenta diversos problemas estruturais.

Figura 9a e 9b: Supermercado Muffato, sua fachada imponente e seu "quintal" pobre

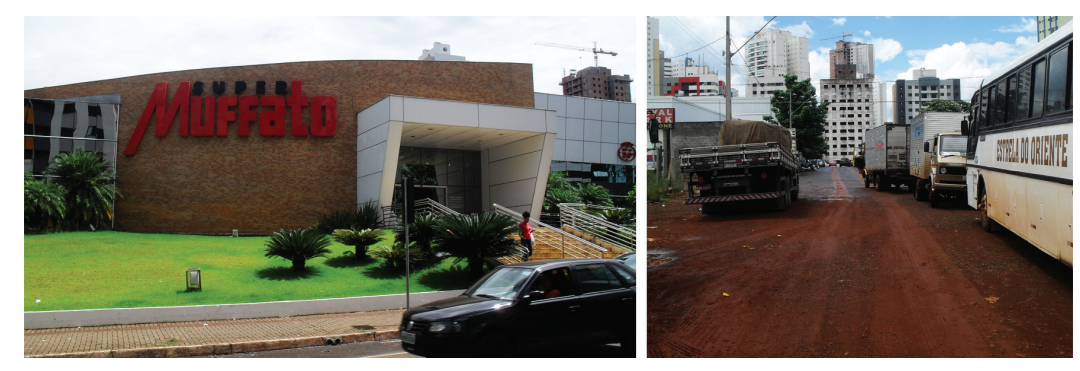

Fonte: Arquivo pessoal do autor

A situação é de gerar certa estranheza, uma vez que a via em questão se localiza imediatamente após o quarteirão que é totalmente composto por um supermercado que se vale de signos de sofisticação e luxo para efetivar o consumo por parte da população que habita o bairro da Gleba Palhano. A construção apresenta muitas características singulares em sua fachada e interior, elementos que são devidamente explorados pelo supermercado. Entretanto, nota-se que não existe uma preocupação com o plano externo quando focamos nos fundos do prédio, isso provavelmente ocorre pelo fluxo baixo de automóveis na regiáo, que apresenta os problemas já citados.

Ao passo que em frente ao estabelecimento comercial está a avenida mais movimentada dos bairros, com todas as suas características de primeiro mundo, ao fundo do quarteirão encontra-se problemas primários de cidades subdesenvolvidas, contrastando totalmente com o requinte que o bairro intenta emanar.

Embora não apresente movimento significativo, as vias sem asfaltar estão muito próximas de dois locais bastante movimentados dos bairros, as Avenidas Madre Leonia Milito e Airton Senna da Silva, na figura 10 pode-se perceber que, logo à frente do terreno baldio, erguem-se alguns edifícios, em contrapartida, o terreno que pertence a rua de chão, os espaços ainda estão sem nenhuma construção.

Figura 10: Rua sem pavimentação próxima a edifícios da Gleba Palhano

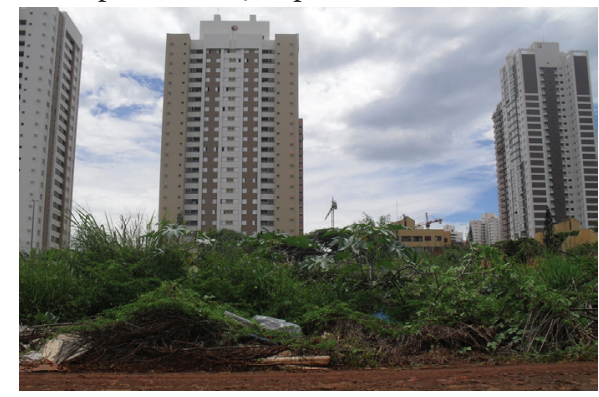

Fonte: Arquivo pessoal do autor 
Nesta perspectiva, vemos que as representaçóes projetadas pelos bairros contrastam em diversos sentidos. Como já citamos, a Gleba Palhano transmite informações que conotam requinte, sofisticação e riqueza estética por meio de signos bem elaborados como os edifícios com detalhes que vão desde as cores do vidros, detalhes em metais e arquitetura rebuscada, até a própria jardinagem externa aos edifícios. Já os bairros Guanabara e Jardim Claudia mantêm como fortes signos os indícios da passagem do tempo e, de certo modo, da tradição destes bairros na cidade de Londrina, uma vez que são mais antigos, como as casas que se apresentam com a arquitetura de décadas anteriores ou com materiais que caíram em desuso (como a madeira, por exemplo), quando comparados às novas construçóes da cidade. Ambos os bairros mantêm em sua imagem urbana a arquitetura simples com formas mais retas de décadas anteriores. No entanto, é perceptível, principalmente no Jardim Claudia, a presença de construçóes que procuram um padrão semelhante ao da Gleba Palhano.

Dessa forma, por meio da vivência e dos usos e hábitos característicos de cada espaço, as pessoas, sejam elas habitantes ou não dessa regiáo, desenvolvem significaçóes que se diferenciam. Ainda que os bairros tenham preponderância na característica habitacional, o modo de morar e de transformar o ambiente em lugar é distinto nestes locais. É fascinante, contudo, a maneira com que as diferenças se manifestam e convivem em espaços tão próximos. Ainda que a forma de significação imposta de modo simbólico pela Gleba Palhano seja bastante dessemelhante dos outros bairros, o ambiente pacífico e convidativo se consagra como um aspecto de todos os ambientes do local estudado.

\section{Conclusáo}

ANo espaço urbano as pessoas se relacionam com o ambiente produzindo diferentes modos de representação. Cada expectador poderá moldar o seu tipo de representação a partir dos usos e hábitos ao qual mantém com cada determinado lugar. Essa representação, entretanto, só poderá surgir assim que o usuário da cidade faça uma racionalização do espaço, isto é, passe a ver a imagem da cidade não mais de modo natural, como mais um elemento do cotidiano, mas sim enquanto lugar que emana determinados sentidos. $\mathrm{O}$ usuário deve estar atento à significação imposta por ele próprio ao lugar.

Neste sentido, enquadram-se os bairros da regiáo sul de Londrina, abordados no estudo. A Gleba Palhano se faz um lugar repleto de significaçóes que emanam contextos de requinte, sofisticação e nobreza, de modo simbólico, ou seja, quando um mesmo objeto, neste caso o bairro, mantém uma significação uniforme a muitos observadores. Vale ressaltar, ainda, que este alto padrão emanado pela Gleba Palhano recebe muito incentivo da mídia, principalmente por meio da propagação de mensagens publicitárias das incorporaçôes imobiliárias, que criam uma verdadeira mitificação ao bairro, originando uma espécie de aura que concede todas as qualidades de riqueza e sofisticação à Gleba Palhano. Entretanto, o bairro é vizinho a dois ambientes que se diferenciam 
potencialmente de suas significaçóes, os bairros Guanabara e Jardim Claudia.

Por apresentar residências humildes e uma arquitetura mais simplória, os bairros Guanabara e Jardim Claudia deixam de emanar todo o poder monetário que a Gleba Palhano transmite. Pelo contrário, eles são carregados de significaçóes de simplicidade e saudosismo, com construçóes que resistem ao tempo em características visuais de um passado não muito distante.

O mais interessante é notar como diferentes modos de representação conseguem conviver de maneira harmoniosa, mesmo diante de tanta heterogeneidade. A calma e o modo simples de vida do bairro Guanabara permanece intacto ao lado da verticalidade dos edifícios de luxo da Gleba Palhano. As ruas silenciosas e pacatas do Jardim Claudia não sofrem interferência do ritmo acelerado que move o bairro vizinho. A vanguarda e o clássico, o calmo e o rápido, o luxo e a simplicidade conseguem conviver lado a lado, quase como se os bairros estivem em três invólucros, que deixa cada um com suas características específicas. No entanto, vale ressaltar, as vias que ligam os bairros sofrem pequenas interferências, principalmente no que tange à arquitetura e à imagem urbana do lugar. É visível que alguns elementos isolados tendem a se manifestar com a pomposidade do bairro vizinho.

Avaliamos que os tipos de representação que os três bairros projetam são totalmente diferenciadas. Cada um se destaca pela qualidade visual de seus elementos, isto é, sua visualidade. Isso acontece graças às características isoladas de cada espaço, pois faz com que os usuários do ambiente mantenham diferentes hábitos com cada uma dessas regiôes. Os usos que são feitos dos lugares dão à imagem urbana diferentes significaçóes, mas, o que é mais evidente, é a forma simbólica com a qual os usuários se relacionam com o bairro da Gleba Palhano.

Assim como no recorte espacial pesquisado, as demais localidades dentro da cidade de Londrina apresentam diferentes formas de representação. A escolha dos três bairros justifica-se pela riqueza sociocultural destes ambientes aliada a ampla heterogeneidade presente entre eles.

Dessa forma, a análise permitiu concluir que, mesmo em uma curta relação espacial, os tipos de representação tidas com o espaço urbano podem sofrer grandes transformaçóes e projetar sentidos totalmente opostos, mas, sem nunca perder a riqueza significante que cada lugar tende a projetar, seja por meio o requinte ou da simplicidade, dos edifícios imponentes ou da casa antiga em madeira. Cada significação trará a sua importância, que é vital para que nós possamos compor as nossas imagens urbanas. 


\section{Referências Bibliográficas}

ACANEVACCI, Massimo. A cidade polifônica. 2. ed. São Paulo: Studio Nobel, 1997.

FERRARA, Lucrécia D’Alessio. A estratégia dos signos: linguagem, espaço, ambiente urbano. São Paulo: Perspectiva, 1986.

_.Design em espaços. São Paulo: Rosari, 2002.

. Olhar periférico. São Paulo: Edusp, 1993.

JANUZZI, Denise de Cássia Rossetto. O desenvolvimento de Londrina e as transformaçóes nos espaços públicos da região central. Semina: Ciências Sociais e Humanas, Londrina, v 26,n.1, p.87-97,set. 2005.

GURAN, Milton. Consideraçôes sobre a constituição e a utilização de um corpus fotográfico na pesquisa antropológica. Discursos Fotográficos. Londrina, v.7, n.10, p.77-106, jan./jun.2011.

LYNCH, Kevin. A imagem da cidade. São Paulo: Martins Fontes, 1999.

ORLANDI, Eni de Lourdes Puccinelli (Org.). Cidade atravessada: os sentidos públicos no espaço urbano. Campinas: Pontes, 2001.

. Cidade dos sentidos. Campinas: Pontes, 2004.

SCHEINKMAN, Sidney. Londrina1-6.jpg. 2012. Altura: 683 pixels. Largura:1024 pixels. 436 Kb. Disponível em: <http://i1141.photobucket. com/albums/n586/ Braulio_Queiroz/CIDADES\%20BRASILEIRAS/ LONDRINA/londrina1-6.jpg>. Acesso em: 16 jan. 2014. 
